\title{
Protection of the human heart with ischemic preconditioning during cardiac surgery: Role of cardiopulmonary bypass
}

Sudip Ghosh, MD

Manuel Galiñanes, MD, PhD, FRCS
From the Department of Integrative Human Cardiovascular Physiology and Cardiac Surgery, University of Leicester, Glenfield Hospital, Leicester, United Kingdom.

This study was supported by a personal contribution from Professor Manuel Galiñanes.

Received for publication April 15, 2002; accepted for publication July 15, 2002.

Address for reprints: Professor M. Galiñanes, Department of Integrative Human Cardiovascular Physiology and Cardiac Surgery, University of Leicester, Glenfield Hospital, Leicester LE3 9QP, United Kingdom (E-mail: sudip.ghoshglenfield-tr.trent.nhs.uk).

J Thorac Cardiovasc Surg 2003;126:133-42

Copyright $(\odot) 2003$ by The American Association for Thoracic Surgery

$0022-5223 / 2003 \$ 30.00+0$

doi:10.1016/S0022-5223(02)73293-5
Objective: Studies on the effects of ischemic preconditioning in the human heart have yielded conflicting results and therefore remain controversial. This study investigated whether ischemic preconditioning was able to protect against myocardial tissue damage in patients undergoing coronary artery surgery with cardiopulmonary bypass and on the beating heart.

Methods: A total of 120 patients were studied and divided into 3 groups: group I: cardiopulmonary bypass with intermittent crossclamp fibrillation; group II: cardiopulmonary bypass with cardioplegic arrest using cold blood cardioplegia; group III: surgery on the beating heart. In each group $(\mathrm{n}=40)$, patients were randomly subdivided $(\mathrm{n}=$ 20/subgroup) into control and preconditioning groups (1 cycle of 5 minutes of ischemia/5 minutes reperfusion before intervention). Ischemic preconditioning was induced by clamping the ascending aorta in groups I and II or by clamping the coronary artery in group III. Serial venous blood levels of troponin T were analyzed before surgery and at $1,4,8,24$, and 48 hours after termination of ischemia. In addition, in vitro studies using right atrial specimens obtained before the institution of cardiopulmonary bypass, and then again 10 minutes after initiation of bypass, were performed. The specimens were equilibrated for 30 minutes before being allocated to 1 of the following 2 groups ( $n=6$ per group): (1) ischemia alone (90 minutes of ischemia followed by 120 minutes of reoxygenation) or (2) preconditioning with 5 minutes of ischemia and 5 minutes of reoxygenation before the long ischemic insult. Creatine kinase leakage (U/g wet weight) and 3-(4,5-dimethylthiazol-2-yl)-2,5-diphenyltetrazolium bromide reduction ( $\mathrm{mmol} / \mathrm{l}$ per gram wet weight), an index of cell viability, were assessed at the end of the experiment.

Results: There were no perioperative myocardial infarctions or deaths in any of the groups studied. The total release of troponin T was similar in groups I and II (patients undergoing surgery with cardiopulmonary bypass) and in the release profile; they were unaffected by ischemic preconditioning. In contrast, the total troponin $\mathrm{T}$ release for the first 48 hours was significantly reduced by ischemic preconditioning in group III (patients undergoing surgery without cardiopulmonary bypass) from $3.1 \pm 0.1$ to $2.1 \pm$ $0.2 \mathrm{ng} \cdot \mathrm{h} \cdot \mathrm{mL}$. Furthermore, the release profile that peaked at 8 hours in the control group shifted to the left at 1 hour. In the in vitro studies, the atrial muscles obtained before cardiopulmonary bypass were protected by ischemic preconditioning (creatine kinase $=2.6 \pm 0.2$ and 3-[4,5-dimethylthiazol-2-yl]-2,5-diphenyltetrazolium bromide reduction $=152 \pm 24$ vs creatine kinase $=5.4 \pm 0.6$ and 3-[4,5dimethylthiazol-2-yl]-2,5-diphenyltetrazolium bromide reduction $=87 \pm 16$ in controls; $P<.05$ ); however, the muscles obtained 10 minutes after initiation of cardiopulmonary bypass were already protected (creatine kinase $=0.8 \pm 0.1$ and 3-[4,5-dimethylthiazol-2-yl]-2,5-diphenyltetrazolium bromide reduction $=316 \pm$ 38 ), and ischemic preconditioning did not result in further improvements.

Conclusions: Ischemic preconditioning is protective in patients undergoing coronary artery surgery on the beating heart without the use of cardiopulmonary bypass, but it offers no additional benefit when associated with bypass regardless of the mode of cardioprotection used, because cardiopulmonary bypass per se induces preconditioning. 


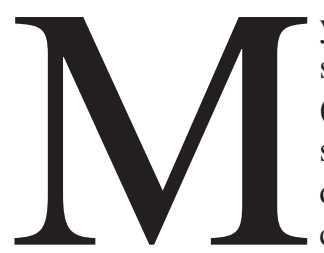

yocardial injury, manifested as transient cardiac contractile dysfunction ("stunning") and myocardial necrosis, is the most frequent complication during heart surgery. ${ }^{1}$ Ischemic preconditioning (IP), a powerful form of endogenous protection against stunning and infarction, has been demonstrated in a variety of animal species ${ }^{2-4}$ and in vitro experiments involving isolated human cardiomyocytes $^{5}$ and human atrial trabeculae. ${ }^{6,7}$ For logistic and ethical reasons, no clinical study can meet the strict conditions of experimental studies on preconditioning with infarct size as the end point. As a result, human in vivo studies have produced conflicting results, and the role of IP in humans remains controversial.

Yellon and coworkers ${ }^{8}$ were the first to report that IP protects the human heart in the setting of cardiac surgery by use of the conservation of myocardial adenosine triphosphate (ATP) content as the major end point. However, Perrault and colleagues ${ }^{9}$ reported that in the presence of cardioplegic arrest, there was no difference in the release of biochemical markers (CK-MB) between the preconditioned and control groups. The lack of additional protection conferred by IP was further confirmed by the absence of difference in the postarrest myocardial levels of ribonucleic messengers coding for cardioprotective heat shock proteins between the 2 groups. Similar negative results were reported by Kaukoranta, ${ }^{10}$ Di Salvo, ${ }^{11}$ and their colleagues, who went on to report that in the presence of hypothermia, no beneficial effect of preconditioning was observed in similar patients undergoing surgery with intermittent fibrillation techniques.

The apparent discrepancy between results obtained with noncardioplegic and cardioplegic techniques could be reconciled if one takes into account a possible hypothesis: Preconditioning and its salutary effects are only observed in situations of unprotected ischemia. With this in mind, this study (1) investigates whether IP with 5 minutes of ischemia followed by 5 minutes of reperfusion is protective in patients undergoing coronary artery bypass graft surgery with cardiopulmonary bypass (CPB) using cardioplegia and ventricular fibrillation techniques and in patients undergoing coronary artery bypass graft surgery on the beating heart without CPB and (2) elucidates the underlying cause of any protection.

\section{Methods \\ In Vivo Studies}

Patient selection and study groups. A total of 120 patients with stable angina who underwent operations performed by a single surgeon (M.G.) were entered in the study. They were divided into 2 groups: those undergoing surgery with CPB (ie, on-pump) and exhibiting 3-vessel coronary disease $(n=80)$ and those undergoing surgery on the beating heart without CPB (ie, off-pump) and with single- or double-vessel coronary artery disease $(n=40)$. Patients in the CPB group were randomized by use of a computer-generated random table to undergo surgery (1) with CPB and intermittent crossclamp fibrillation \pm IP $(n=20$ in each subgroup) or (2) with cold blood cardioplegia \pm IP ( $n=20$ in each subgroup). Similarly, patients undergoing surgery on the beating heart without CPB were randomized to receive or not receive IP (n $=20$ in each subgroup). IP was induced by clamping the ascending aorta for 5 minutes at $37^{\circ} \mathrm{C}$ when $\mathrm{CPB}$ was used or by occluding the coronary artery to be grafted for the same period and then reperfusing for 5 minutes before the bypass graft was performed. We have demonstrated that this IP protocol is the most protective in the human myocardium. ${ }^{7}$ Patients with low ejection fractions $(<30 \%)$, unstable angina, recent myocardial infarctions $(<1$ month), additional cardiac diseases, severe noncardiac diseases, or diabetes, and who were receiving medication that included ATP-dependent potassium channel $\left(\mathrm{K}_{\mathrm{ATP}}\right)$ openers were excluded. The study was approved by the local ethics committee, and all patients gave written informed consent to participate in the study. Preoperative characteristics of the patients are highlighted in Table 1.

Operative procedure. Anesthetic technique was standardized for all patients. Anesthesia was induced by fentanyl and maintained with enflurane in all patients. All operations were performed through a median sternotomy and with full heparinization (3 $\mathrm{mg} / \mathrm{kg}$ intravenously). CPB was conducted with nonpulsatile perfusion flow $\left(2.2-2.4 \mathrm{~L} \cdot \mathrm{min}^{-1} \cdot \mathrm{m}^{-2}\right)$ with ascending aortic cannulation and 2-staged venous cannulation and moderate systemic hypothermia $\left(32^{\circ} \mathrm{C}\right)$. When cardiac arrest was achieved with cold blood $\left(6-10^{\circ} \mathrm{C}\right)$ cardioplegia, $1000 \mathrm{~mL}$ of the solution (composition in mmol/L: $16 \mathrm{MgCl}_{2} 6 \mathrm{H}_{2} 0 ; 2 \mathrm{CaCl}_{2} ; 20 \mathrm{KCl} ; 147$ $\mathrm{NaCl} ; 1.0$ procaine $\mathrm{HCl}, \mathrm{pH} 7.40$ ) was mixed with blood from the pump in a ratio of $1: 1$ and injected into the aortic root immediately after aortic crossclamping to obtain a myocardial temperature of $12^{\circ} \mathrm{C}$ to $15^{\circ} \mathrm{C}$. An additional dose of $500 \mathrm{~mL}$ of cardioplegic solution was injected after 30 minutes of ischemia. In the group in which intermittent aortic crossclamp fibrillation was used, reperfusion was performed for 3 minutes between each period. One single distal coronary artery anastomosis was performed during each ischemic period. Proximal anastomosis was completed on the beating heart with an aortic partial occlusion clamp in all groups.

In the off-pump group, coronary bypass grafting was performed on the beating heart using the Octopus myocardial stabilization device (Medtronic Inc., Minneapolis, Minn). The suction cups were placed on the epicardial surface on either side of the artery to be grafted, with a suction pressure of no more than $600 \mathrm{~mm} \mathrm{Hg}$. Small coronary clamps were applied to the proximal and distal sites of the anastomosis with just enough pressure to occlude coronary flow and therefore allow grafting in a bloodless field. The clamps were released when the anastomosis was complete. The proximal anastomosis was performed with a partial occlusion aortic clamp.

IP was applied before the first dose of cardioplegic solution or immediately before the aortic cross-application or the coronary artery occlusion. The use of a Khuri Tissue $\mathrm{pH}$ Analyzer (Vascular Tech, Boston, Mass) showed that the $\mathrm{pH}$ of the myocardium 
TABLE 1. Patient characteristics and perioperative data

\begin{tabular}{|c|c|c|c|c|c|c|}
\hline \multirow[b]{3}{*}{ Variable } & \multicolumn{4}{|c|}{ With CPB } & \multicolumn{2}{|c|}{ Without CPB } \\
\hline & \multicolumn{2}{|c|}{ Intermittent crossclamp } & \multicolumn{2}{|c|}{ Cold blood cardioplegia } & \multirow[b]{2}{*}{ Control } & \multirow[b]{2}{*}{ PC } \\
\hline & Control & PC & Control & PC & & \\
\hline Number & 20 & 20 & 20 & 20 & 20 & 20 \\
\hline Age $(y r \pm S D)$ & $66.9 \pm 5.4$ & $63.7 \pm 4.2$ & $61.4 \pm 9.2$ & $63.8 \pm 5.9$ & $61.2 \pm 2.7$ & $59.2 \pm 6.4$ \\
\hline $\operatorname{LVEF}(\% \pm \mathrm{SD})$ & $60.2 \pm 5.5$ & $61.8 \pm 4.1$ & $62.1 \pm 5.7$ & $63.7 \pm 4.9$ & $59.7 \pm 9.2$ & $65.1 \pm 6.4$ \\
\hline No. of grafts/patient & $3.8 \pm 1.5$ & $3.6 \pm 0.8$ & $3.7 \pm 1.2$ & $4.1 \pm 0.7$ & $1.15 \pm 0.6$ & $1.2 \pm 0.5$ \\
\hline $\begin{array}{l}\text { Ischemic time/graft } \\
(\min \pm S D)\end{array}$ & $16.1 \pm 2.5$ & $15.4 \pm 3.1$ & $17.2 \pm 4.9$ & $14.7 \pm 5.7$ & $17.8 \pm 7.9$ & $16.9 \pm 4.7$ \\
\hline CPB time $(\min \pm S D)$ & $66.4 \pm 12.7$ & $70.4 \pm 11.4$ & $71.4 \pm 13.4$ & $69.8 \pm 6.7$ & & \\
\hline
\end{tabular}

$P C$, Preconditioning; $L V E F$, left ventricular ejection fraction (expressed as a percentage \pm standard deviation); $C P B$, cardiopulmonary bypass.

decreased from greater than 7.3 to less than 7.0 at the end of the 5-minute IP insult in all cases.

Assessment of myocardial injury. Serial venous blood samples were collected before induction of anesthesia and at $1,4,8$, 24 , and 48 hours after termination of ischemia in every patient for the assessment of troponin $\mathrm{T}(\mathrm{TnT})$. This was measured by use of the commercially available enzyme-linked immunoabsorbent assay kit TnT (Boehringer Mannheim, Mannheim, Germany). The lower detection limit of the assay was $0.05 \mathrm{ng} / \mathrm{mL}$, and concentrations greater than the discriminator value of $0.1 \mathrm{ng} / \mathrm{mL}$ were considered elevated.

Hemodynamic measurements. Heart rate, mean pulmonary artery pressure, pulmonary capillary wedge pressure, and cardiac output were monitored with a pulmonary artery flotation catheter. Derived cardiovascular variables, including cardiac index and systemic and pulmonary vascular resistance, were calculated by standard formulas. Hemodynamic data were collected at 4 time points: baseline (just after induction of anesthesia) and 1, 3, and 24 hours after the termination of ischemia. Changes in derived variables were calculated and compared.

\section{In Vitro Studies}

Specimens of human right atrium appendage were obtained from patients undergoing elective coronary artery surgery with CPB. Samples were obtained before the institution of CPB and again 10 minutes after the initiation of CPB. Two 6-0 Prolene (Ethicon Inc, Somerville, NJ) encircling sutures were placed in the epicardial layer of the appendage once the pericardium was opened. During the entire period of harvesting, the atrium was exposed to the systemic circulation. The prebypass sample was then harvested, and a 2-stage venous cannula was inserted in the free wall of the right atrium $3 \mathrm{~cm}$ away from the appendage. $\mathrm{CPB}$ was then instituted, and after 10 minutes, a further sample of appendage was harvested. In each case, specimens were quickly immersed in cold $\left(4^{\circ} \mathrm{C}\right)$ Krebs-Henseleit-HEPES medium, which comprised (in micromoles per liter) $\mathrm{NaCl}, 118$; $\mathrm{KCl}, 4.8 ; \mathrm{NaHCO}_{3}, 27.2 ; \mathrm{KH}_{2} \mathrm{PO}_{4}, 1 ; \mathrm{MgCl}_{2}, 1.2 ; \mathrm{CaCl}_{2}, 1.25$; glucose, 10; and HEPES, 20. The medium was pre-bubbled with $95 \% \mathrm{O}_{2} / 5 \% \mathrm{CO}_{2}$ to attain $\mathrm{PO}_{2}$ of 25 to $30 \mathrm{kPa}$ and $\mathrm{pH}$ 7.4. The atrial appendage was immediately sliced freehand with SwannMorton skin graft blades (Swann-Morton Ltd, Sheffield, United Kingdom) to a thickness of 0.3 to $0.5 \mathrm{~mm}$ and a weight of 5 to
$10 \mathrm{mg}$ each, as previously described. ${ }^{12}$ In brief, the tissue was placed with its epicardial surface face down on filter paper fixed to a rectangular glass base $(5 \times 25 \mathrm{~cm})$. A ground glass slide $(2.5 \times 7.5 \mathrm{~cm})$ was then pressed against the tissue, and the blade was drawn between the slide and tissue. The slicing apparatus and the tissue were kept wet at all times with medium that was stored on ice $\left(4^{\circ} \mathrm{C}-10^{\circ} \mathrm{C}\right)$. The specimens were equilibrated for 30 minutes before being randomly allocated to 1 of the following 2 groups ( $\mathrm{n}=6$ each from different patients/group): (1) ischemia alone ( 90 minutes of ischemia followed by 120 minutes of reperfusion) or (2) IP with 5 minutes of ischemia and 5 minutes of reperfusion before 90 minutes of ischemia followed by 120 minutes of reperfusion. For the induction of simulated ischemia, the medium was bubbled with $95 \% \mathrm{~N}_{2} / 5 \% \mathrm{CO}_{2}(\mathrm{pH} 6.80-7.00)$, and D-glucose was removed and substituted with D-2-deoxyglucose $(10 \mathrm{mmol} / \mathrm{L})$. The slices were maintained at $37^{\circ} \mathrm{C}$ during the entire ischemic period. Monitoring of $\mathrm{Po}_{2}$ with an oxygen detector electrode (Oxylite; Oxford, United Kingdom) revealed that the $\mathrm{PO}_{2}$ in the medium was $0 \mathrm{kPa}$. Tissue $\mathrm{pH}$ was not measured in the atrial sections. At the end of the ischemic period, the nonoxygenated medium was removed, and the slices were rinsed with oxygenated medium $\left(\mathrm{O}_{2} / \mathrm{CO}_{2}, 19: 1\right)$ and incubated in $5 \mathrm{~mL}$ of oxygenated medium containing $10 \mathrm{mmol} / \mathrm{L}$ glucose at $37^{\circ} \mathrm{C}$ for a further 120 minutes.

Tissue injury was determined by measuring the leakage of creatine kinase $(\mathrm{CK})$ into the incubation medium during the 120-minute reperfusion period. This was assayed by a kinetic ultraviolet method based on the formation of nicotinamide adenine dinucleotide (Sigma Catalog No. 1340-K), and the results were expressed as U/g wet weight. Tissue viability was assessed by the reduction of 3-(4,5-dimethylthiazol-2-yl)-2,5 diphenyltetrazolium bromide (MTT) to blue formazan product at the end of the experimental time. In this assay, the yellow MTT is reduced to a blue formazan product by the mitochondria of viable tissue.

The tissue was loaded into a Falcon conical tube $(15 \mathrm{~mL})$ (Becton Dickinson Labware, Franklin Lakes, NJ) to which $2 \mathrm{~mL}$ of phosphate buffer solution $(0.05 \mathrm{~mol} / \mathrm{L})$ containing MTT (1.25 $\mathrm{mg} / \mathrm{mL}, 3 \mathrm{mmol} / \mathrm{L}$ at final concentration) was added and then incubated for 30 minutes at $37^{\circ} \mathrm{C}$. After this, the tissue was homogenized in $2 \mathrm{~mL}$ of dimethyl sulfoxide (Homogenizer UltraTurrax T25, dispersing tool G8, IKA-Labortechnic, Staufen, Ger- 
TABLE 2. Patients' hemodynamic data

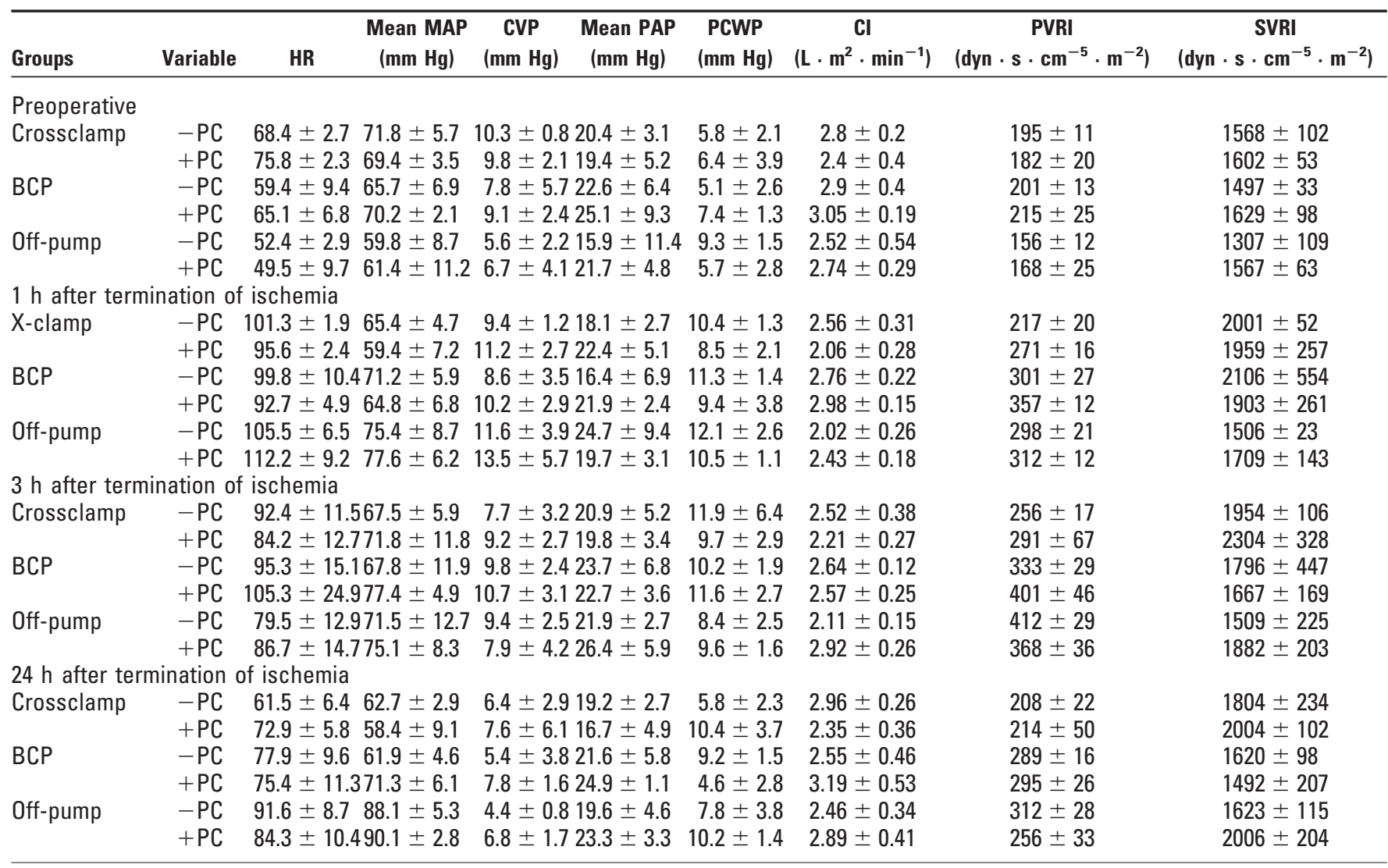

$B C P$, Blood cardioplegia; $C l$, cardiac index; $C V P$, central venous pressure; $H R$, heart rate; $M A P$, mean arterial pressure; $P A P$, pulmonary artery pressure; $P C W P$, pulmonary capillary wedge pressure; $P V R I$, pulmonary vascular resistance index; $S V R I$, systemic vascular resistance index. Data are expressed as mean \pm standard deviation.

many) at $9500 \mathrm{rpm}$ for 1 minute. The homogenate was then centrifuged at $1000 \mathrm{~g}$ for 10 minutes, and $0.2 \mathrm{~mL}$ of the supernatant was dispensed into a 98-well flat-bottom microtiter plate (Nunc Brand Products, Denmark). After this, the absorbance was measured on a plate reader (Benchmark; Bio-Rad Laboratories, Hercules, Calif) at $550 \mathrm{~nm}$, and the results were expressed as micromoles per liter per milligram wet weight.

\section{Statistical Analysis}

Statistical analyses were performed using the SPSS 9.0 statistical package program (SPSS Inc, Chicago, Ill) to investigate the efficacy of IP in the various groups of patients. Patients undergoing surgery without $\mathrm{CPB}$ demonstrated less severe coronary artery disease than those undergoing surgery with CPB (Table 2), and because of this, comparison between patients with and without CPB was not performed. A nonparametric test (Mann-Whitney $U$ ) was performed for non-Gaussian distribution of data. An unpaired Student $t$ test was used for continuous data (2-tailed), and the $\chi^{2}$ test for categoric data was used to compare variables between the groups. Repeated-measures analysis of variance was used to test the repeated observation variables postoperatively. The area under the curve was calculated by the method of Matthews and colleagues. ${ }^{13}$ Data were presented as mean $\pm \mathrm{SD}$.

\section{Results}

\section{In Vivo Studies}

There were no operative deaths (first 30 postoperative days) or perioperative myocardial infarctions in any of the study groups. Table 1 shows that the patient characteristics and perioperative data were similar within each study group, and that there was no difference between patients who were treated with or without IP.

\section{Plasma Troponin $T$}

Figure 1 (A and B) shows that the profile of TnT release in plasma was identical in patients undergoing coronary surgery with $\mathrm{CPB}$ whether they were protected with intermittent fibrillation or cold blood cardioplegia. Thus, there was a significant increase in plasma TnT by 1 hour after termination of ischemia that peaked at 4 hours, with mean values still remaining elevated at 48 hours. Notably, preconditioning did not alter this profile in both groups, indicating that preconditioning conveys no benefit to patients undergoing coronary surgery with CPB. 


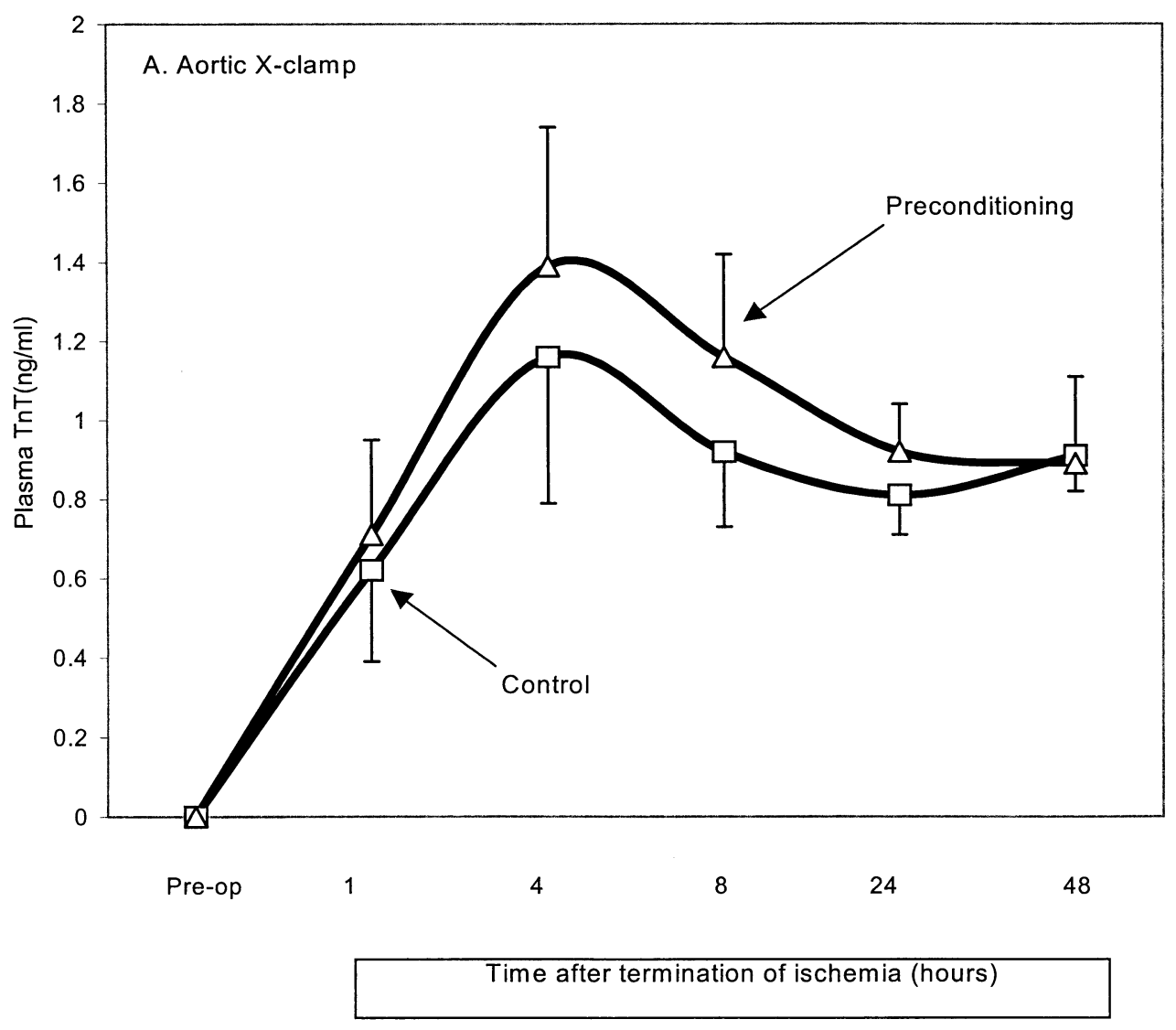

Figure 1A. Time course of release of plasma cardiac troponin $\mathrm{T}(\mathrm{TnT})$ concentrations in patients undergoing coronary artery bypass grafting with CPB and aortic crossclamping. In each group, patients were randomly subdivided into control and preconditioning groups $\left(n=20 /\right.$ group). Data are expressed as mean \pm SD $\left({ }^{*} P<.05\right.$ vs control group).

In contrast, as shown in Figure 1C, the profiles of plasma TnT were different in patients with or without preconditioning and off-pump surgery. Peak release occurred by 8 hours after termination of ischemia in the control group. Peak release occurred by 1 hour in the preconditioned group with a sharp decrease during the next 3 hours and with significantly lower mean plasma TnT values than in the control group. The significance of the accelerated rate of enzyme leakage in the preconditioning group is not entirely clear, but it could be the result of changes within the biophysical properties induced by IP (thus allowing a greater transient leakage of intracellular enzymes) or of greater cumulative ischemic time in the preconditioned group compared with the control group. TnT levels were similar in both groups only by the end of 48 hours.

Figure 2 shows that the cumulative plasma release of TnT (ie, area under the curve) was similar in the patients undergoing surgery with CPB with no significant effect of preconditioning. It also shows that $\mathrm{TnT}$ release was lower in patients undergoing surgery without $\mathrm{CPB}$, and that precon- ditioning in this group significantly reduced the total $\mathrm{TnT}$ release by $33 \%$ when compared with the control group ( 2.1 \pm 0.1 vs $\left.3.1 \pm 2 \mathrm{ng} \cdot \mathrm{h}^{-1} \cdot \mathrm{mL}^{-1} P<.05\right)$.

\section{Hemodynamic Data}

Table 2 shows that the mean systemic arterial pressures, heart rate, mean pulmonary artery pressures, systemic and pulmonary vascular resistance, and cardiac indices fluctuated within normal ranges after the operation in both the control and preconditioned groups and in the groups with and without CPB.

\section{In Vitro Studies}

Figure 3 (A and B) shows the results of the CK leakage and MTT reduction of the atrial slices obtained before bypass and 10 minutes after initiation of CPB. The results demonstrate that the increase in CK leakage and the decrease in MTT reduction caused by ischemia and reoxygenation in the atrial muscles obtained before the institution of bypass were significantly improved in the slices obtained 10 min- 


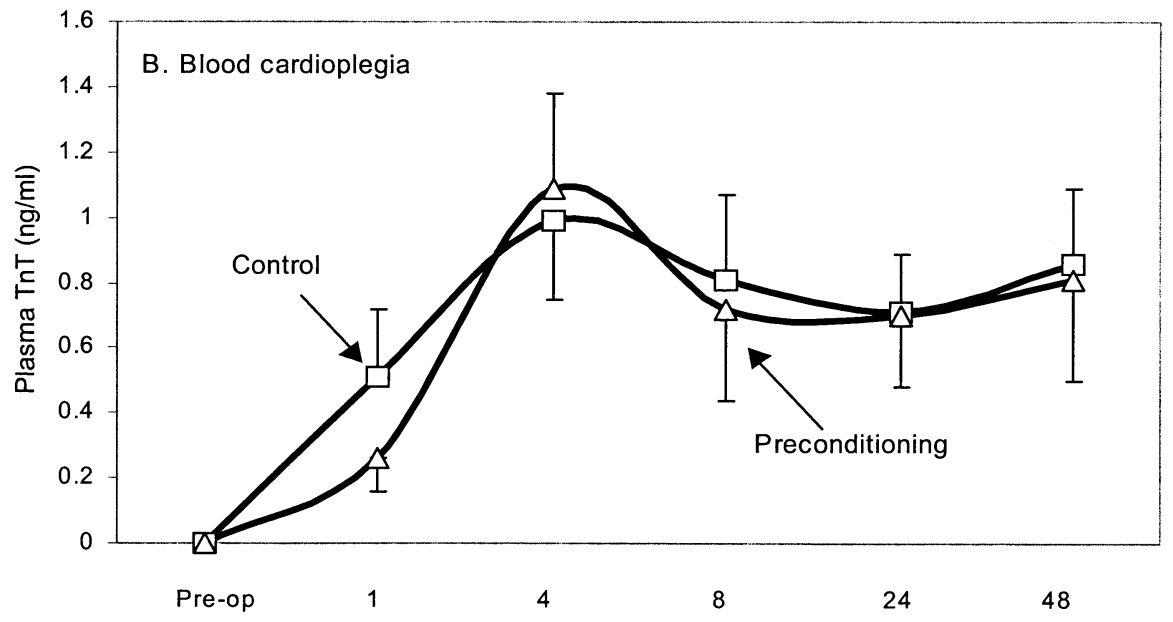

Time after termination of ischemia (hours)

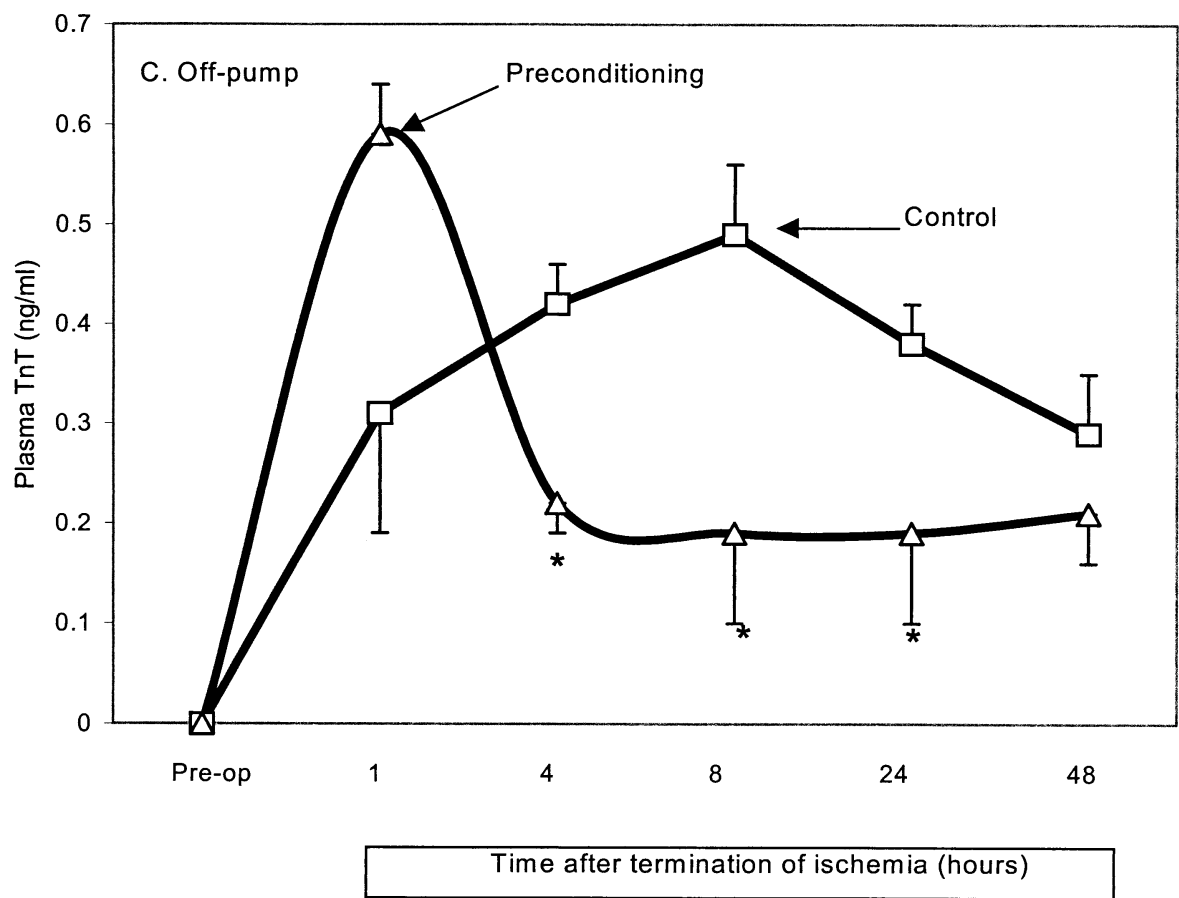

Figure 1. Cont'd. Time course of release of plasma cardiac TnT concentrations in patients undergoing coronary artery bypass grafting with CPB and cold blood cardioplegia (B) and on the beating heart without CPB (C). In each group, patients were randomly subdivided into control and preconditioning groups (n $=20 /$ group). Data are expressed as mean $\pm S D(* P<.05$ vs control group).

utes after the initiation of bypass, and that this level of protection was identical to that of preconditioning. Thus, muscles that were obtained 10 minutes after the initiation of bypass were already preconditioned, and the application of IP did not result in additional benefit compared with IP alone.

\section{Discussion}

The present study shows that the human heart is preconditioned by the institution of $\mathrm{CPB}$, and that the use of IP in combination with other protective interventions such as cardioplegia does not result in additional protection. It also clearly demonstrates that the human heart can be protected 


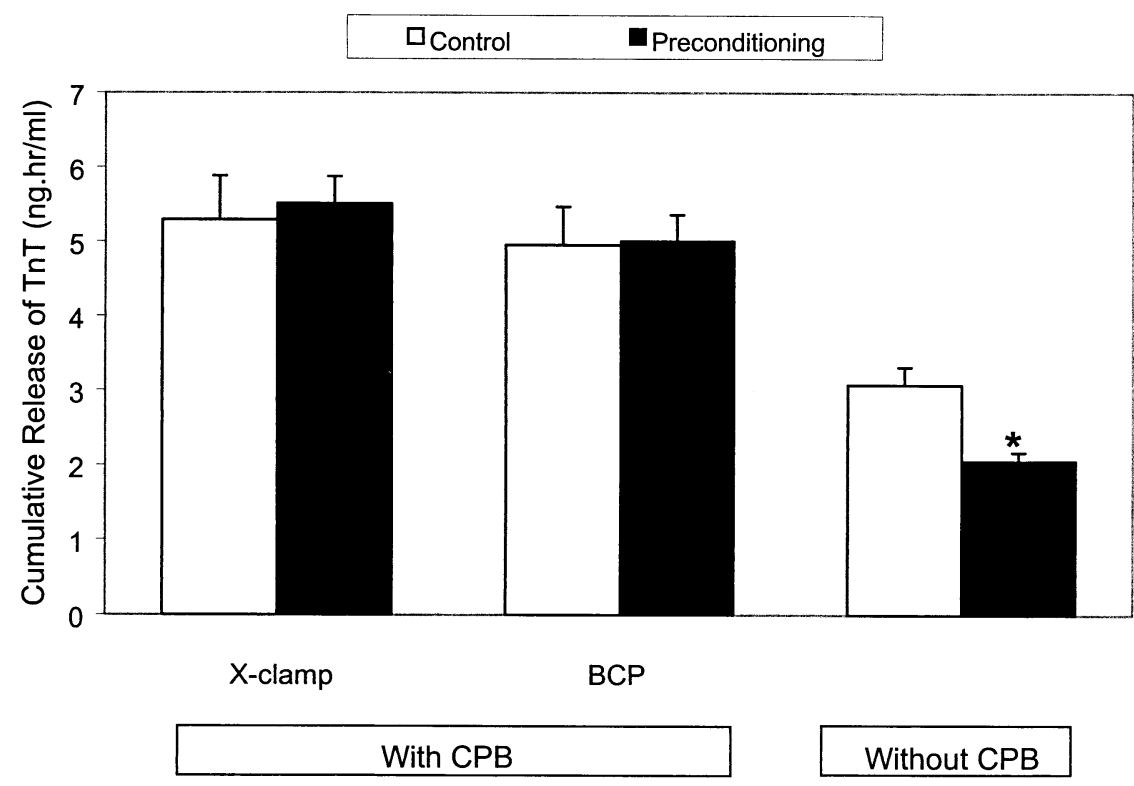

Figure 2. Area under the curve of the plasma release cardiac $\mathrm{TnT}$ in patients undergoing coronary artery bypass grafting with CPB and aortic crossclamping, CPB and cold blood cardioplegia, and on the beating heart without CPB ( $P^{*}<.05$ vs corresponding control group).

by IP when patients undergo surgery without the use of CPB. These findings have obvious important clinical implications, and they warrant further discussion.

\section{Preconditioning of the Human Heart}

Experimental findings on IP cannot be directly extrapolated to humans because the mechanisms may be different from other animal species. For both logistic and ethical reasons, no clinical study can meet the strict conditions of experimental studies on preconditioning in which infarct size is the primary end point; instead, surrogate end points have to be used. As a result, the demonstration of this phenomenon in the setting of cardiac surgery has been controversial. Yellon and colleagues ${ }^{8}$ were the first to examine the effect of two 3-minute ischemic episodes, in which each was followed by 2-minute reperfusion on myocardial high-energy phosphate content, in patients undergoing coronary artery bypass graft surgery with CPB. They claimed that the human myocardium showed the typical biochemical features of preconditioning observed by Murry and colleagues ${ }^{14}$ in their classic canine model of IP and thus could be preconditioned. There have been recent studies ${ }^{15,16}$ also highlighting the potential benefits of preconditioning in the cardiac surgery setting. However, Perrault and associates ${ }^{9}$ failed to show a beneficial effect of IP when this was induced with 3-minute aortic crossclamping followed by 2-minute reperfusion before the administration of warm blood cardioplegia. Similar findings have been reported by other investigators ${ }^{10,17}$ questioning the ability of precondi- tioning to protect the human heart. The dispute on whether preconditioning confers cardioprotection during cardiac surgery is further fueled by a more recent study by Alkhulafi and colleagues. ${ }^{18}$ By use of a protocol identical to the one used in their first study, ${ }^{8}$ Alkhulafi and coworkers showed a reduction of TnT release at 72 hours in patients exposed to preconditioning, but not at 24 or 48 hours. Notably, the same authors reported an absence of protection in myocardial high-energy phosphates (in contrast with their first study). These opposing results are puzzling and contrast with the overwhelming evidence that preconditioning is cardioprotective during coronary angioplasty ${ }^{19}$ and in vitro experimental conditions using atrial trabeculae ${ }^{6,7}$ or isolated myocytes. ${ }^{20}$ Our finding that $\mathrm{CPB}$ can act as a preconditioning stimulus in humans is supported by another study in sheep $^{21}$ and sheds light on the previously mentioned controversy.

During cardiac surgery, there may be preoperative and intraoperative factors such as opioid agonists ${ }^{22}$ and anesthetic agents ${ }^{23}$ that may mimic the protection of preconditioning. These include the use of opioid agonists, aprotinin, and, notably, CPB. It has been reported that inhalational anesthetics can induce cardioprotection, and that this effect differs with the agent used. ${ }^{24,25}$ In the present study, enflurane was used. Although enflurane is less effective than other inhalational anesthetics, ${ }^{24}$ and IP was shown to be cardioprotective in the off-pump group, it may not be possible to completely rule out some protective effect caused 

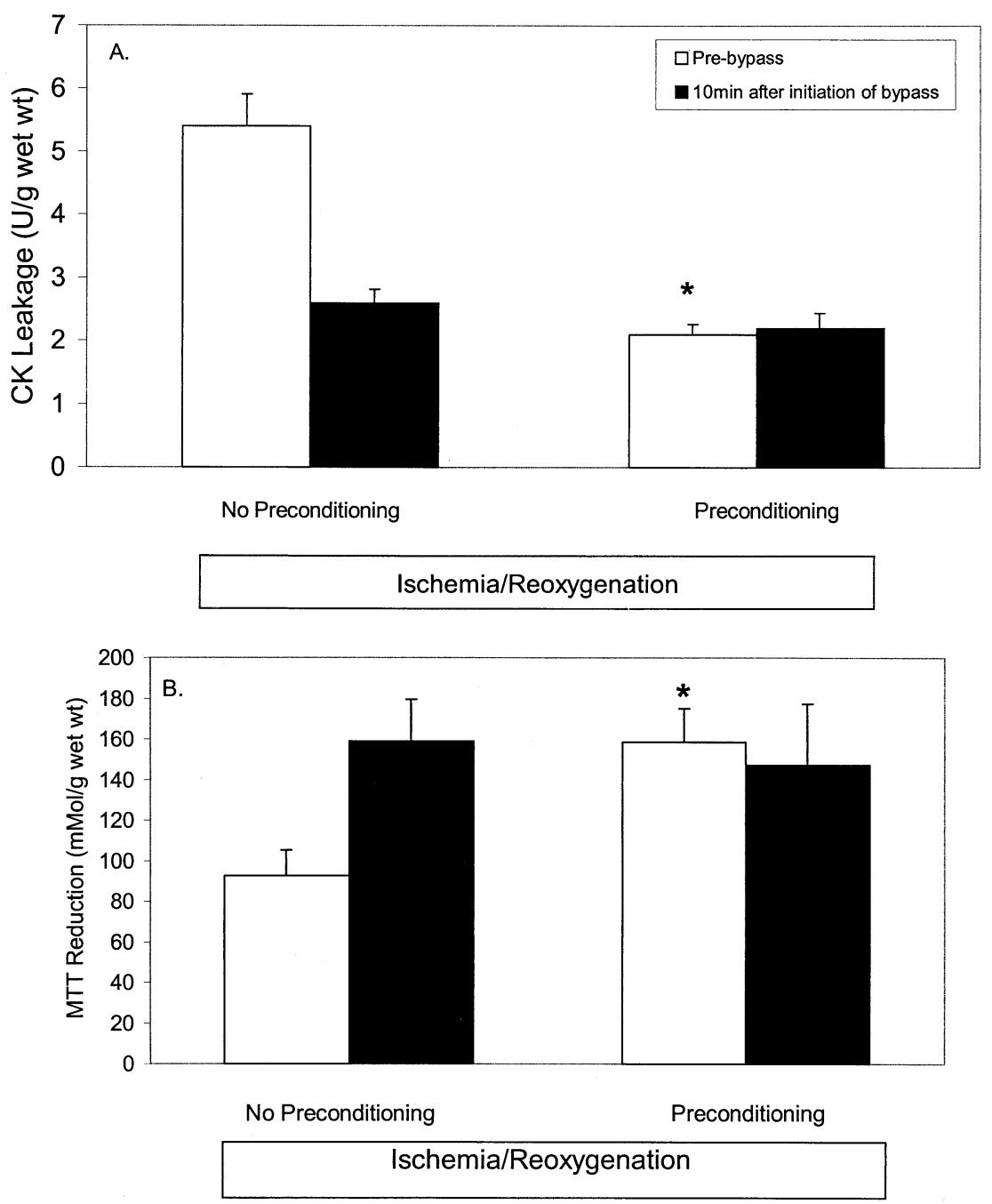

Figure 3. CK leakage (A) during the 120-minute reoxygenation period and MTT reduction (B) at the end of the reoxygenation period after $\mathbf{9 0}$ minutes of normothermic global ischemia with or without simulated IP. Data are expressed as mean \pm SD of 6 experiments ${ }^{*} P<.05$ vs corresponding group without preconditioning).

by this agent. Hypothermia is another cardioprotective fac$\operatorname{tor}^{26}$ that may influence the cardioprotection of preconditioning. Recently, Takeshima and colleagues ${ }^{27}$ also demonstrated that preconditioning was not protective with deep hypothermia. However, moderate hypothermia alone, as used in the present studies, does not inhibit the preconditioning response.

\section{Mechanism of Preconditioning by Cardiopulmonary Bypass}

Although the precise mechanism of IP still remains unclear, recent investigations have clearly identified a number of factors that are essential to achieve protection. CPB induces a systemic inflammatory reaction, and it is possible that some elements of this reaction may be responsible for the observed protection. Yamashita and coworkers ${ }^{28}$ recently reported that interleukin 1 and tumor necrosis factor $\alpha$ (the production of which is increased by $\mathrm{CPB}$ ) cause an elevation in tissue manganese-superoxide dismutase, which was demonstrated when brief sublethal ischemia or anoxic insults were induced. ${ }^{29}$ However, this thesis is unlikely, because the production of cytokines is a late event in response to $\mathrm{CPB}$ that requires more than 10 minutes.

Recently, our laboratory showed that the generation of free radical species occurs soon after the institution of CPB. ${ }^{30}$ Therefore, it is possible to speculate that free radicals are the primary cause of cardioprotection by CPB. The relationship between free radicals and preconditioning was first suggested by Richard and colleagues, ${ }^{31}$ who showed that administration of oxygen free radical scavengers during 
the first reperfusion period could block the beneficial effect of preconditioning on infarct size in dogs. They therefore proposed that the generation of low amounts of free radicals during the short ischemic episode is not sufficient to cause cell necrosis but enough to modify cellular activity and induce preconditioning. More recently, Pain and colleagues $^{32}$ demonstrated that the opening of mitochondrial $\mathrm{K}_{\text {ATP }}$ channels triggers protection through the generation of free radicals that activate protein kinase $\mathrm{C}$, an obligatory step in the signal transduction mechanism of IP. One of the potential limitations with our in vitro studies is the use of atrial myocardium as opposed to ventricular myocardium, and therefore any extrapolation must be conducted with caution; however, Speechly-Dick and coworkers ${ }^{33}$ suggested that preconditioning exerts identical protection in both tissues. Undoubtedly, $\mathrm{K}_{\mathrm{ATP}}$ channels are present in both atrium and ventricle, ${ }^{34}$ although their density in both tissues is unknown.

The induction of CPB affects the body hemodynamics that may provoke a number of tissue responses. Thus, the loss of atrial and ventricular filling may stimulate a sympathetic-receptor-mediated release of local catecholamines, whereas the interruption of pulsatile systolic and diastolic blood flow to the adrenal glands may stimulate a systemic catecholamine release. Therefore, an altered adrenergic state may also be partially responsible for CPB-associated preconditioning in human myocardium. Several investigators,${ }^{35,36}$ including the current authors, ${ }^{37}$ have observed that norepinephrine or phenylephrine triggers preconditioning, and that this protection is prevented by adrenergic blockade. Similarly, Thornton and colleagues ${ }^{38}$ demonstrated that tyramine, an agent that causes the release of endogenous catecholamines, reduced infarct size in rabbits when given before a sustained period of ischemia. Certainly, more studies are required to elucidate the mechanism of cardioprotection effected by CPB.

\section{Clinical Implications}

Cardiac surgical practice is rapidly evolving, and an increasing number of surgeons are adopting surgery on the beating heart, without the use of $\mathrm{CPB}$, in their practice. Cardioplegic solutions cannot be used in this situation, and the demonstration that interventions such as IP are as effective can have important clinical implications. However, it should be recognized that the clinical application of IP may still be difficult and cumbersome, particularly if minimally invasive approaches are used. Because of this, the pharmacologic manipulation of the signal transduction cascade of preconditioning may seem to be a more appropriate alternative. In this regard, several investigators, including the current authors, are endeavoring to fully elucidate the mechanism of preconditioning in humans to make this intervention a clinical reality.
$\mathrm{CPB}$ is known to induce a systemic inflammatory reaction that is believed to be responsible for increased morbidity. The present studies demonstrate that CPB can also trigger preconditioning and be cardioprotective.

\section{References}

1. Breisblatt W, Stein W, Wolfe CJ, et al. Acute myocardial dysfunction and recovery: a common occurrence after coronary bypass surgery. J Am Coll Cardiol. 1990;15:1261-9.

2. Schott RJ, Rohmann S, Braun ER, Schaper W. Ischemic preconditioning reduces infarct size in swine myocardium. Circ Res. 1990;66:113342.

3. Miller DL, Van Winckle DM. Ischemic preconditioning limits infarct size following regional ischemia-reperfusion in in situ mouse hearts. Cardiovasc Res. 1999;42:680-4.

4. Goto M, Liu Y, Yang X-M, Ardell JL, Cohen MV, Downey JM. Role of bradykinin in protection of ischemic preconditioning in rabbit hearts. Circ Res. 1995;77:611-21.

5. Ikonomidis JS, Tumiati LC, Weisel RD, et al. Preconditioning human ventricular cardiomyocytes with brief periods of simulated ischemia. Cardiovasc Res. 1994;28:1285-91.

6. Speechly-Dick ME, Grover GJ, Yellon DM. Does ischemic preconditioning in the human involve PKC and the ATP-dependent $\mathrm{K}^{+}$channel? Circ Res. 1995;77:1020-35.

7. Ghosh S, Standen NB, Galiñanes M. Preconditioning the human myocardium by simulated ischemia. Studies on the early and delayed protection. Cardiovasc Res. 2000;45:339-50.

8. Yellon DM, Alkhulaifi AM, Pugsley WB. Preconditioning the human myocardium. Lancet. 1993;342:276-7.

9. Perrault LP, Menasché P, Bel A, et al. Ischemic preconditioning in cardiac surgery: a word of caution. J Thorac Cardiovasc Surg. 1996; 112:1378-86.

10. Kaukoranta P, Lepojävi MPK, Ylitalo KV, et al. Normothermic retrograde blood cardioplegia with or without preceding ischemic preconditioning. Ann Thorac Surg. 1997;63:1268-74.

11. Di Salvo C, Hemming A, Jenkins D. Can human myocardium be preconditioned with ischaemia under hypothermic conditions? Proceedings of the Ninth Annual Meeting of the European Association for Cardiothoracic Surgery. 1995:324 [Abstract].

12. Zhang JG, Ghosh S, Ockleford CD, Galiñanes M. Characterization of an in vitro model to study the short and prolonged effects of myocardial ischaemia and reperfusion in human myocardium. Clin Sci. 2000; 99:443-53.

13. Matthews JNS, Altman DG, Campbell DJ, et al. Analysis of serial measurements in medical research. BMJ. 1990;300:230-5.

14. Murry CE, Jennings RB, Reimer KA. Preconditioning with ischemia: a delay of lethal injury in ischemic myocardium. Circulation. 1986; 74:1124-36.

15. Wu ZK, Tarkka MR, Pehkonen E, et al. Ischaemic preconditioning has a beneficial effect on left ventricular haemodynamic function after coronary artery bypass grafting operation. Scand Cardiovasc J. 2000; 34:247-53.

16. Szmagala P, Morawski W, Krejca M, et al. Evaluation of peri-operative myocardial tissue damage in ischemically preconditioned human heart during aortocoronary bypass surgery. J Cardiovasc Surg. 1998; 39:791-5.

17. Cremer J, Steinhoff G, Karck M, et al. Ischemic preconditioning prior to myocardial protection with cold cardioplegia in coronary surgery. Eur J Cardiothorac Surg. 1997;12:753-8.

18. Alkhulafi AM, Yellon DM, Pugsley WB. Preconditioning the human heart during aorto-coronary bypass surgery. Eur J Cardiothorac Surg. 1994;8:270-6.

19. Deutsch E, Berger M, Kussmaul WG, et al. Adaptation to ischemia during percutaneous transluminal coronary angioplasty: clinical, haemodynamic and metabolic features. Circulation. 1990;82:2044-51.

20. Cleveland JC Jr, Wollmering MM, Meldrum DR, et al. Ischemic preconditioning in human and rat ventricle. Am J Physiol. 1996;271: H1786-94. 
21. Burns PG, Krukenkamp IB, Caldarone CA, et al. Does cardiopulmonary bypass alone elicit myoprotective preconditioning? Circulation. 1995;92(Suppl II):II447-51.

22. Schultz JEL, Rose E, Yao Z, Gross GJ. Evidence for the involvement of opioid receptors in ischemic preconditioning in rat hearts. Am J Physiol. 1995;268:H2157-61.

23. Cope DK, Impastato WK, Cohen MV, Downey JM. Volatile anesthetics protect the ischemic rabbit myocardium from infarction. Anesthesiology. 1997;86:699-709.

24. Schlack W, Preckel B, Stunneck D, Thamer V. Effects of halothane, enflurane, isoflurane, sevoflurane and desflurane on myocardial reperfusion injury in the isolated rat heart. Br J Anaesth. 1998;81:913-19.

25. Preckel B, Schlack W, Confere T, Obal D, Barthel H, Thamer V. Effects of enflurane, isoflurane, sevoflurane and desflurane on reperfusion injury after regional myocardial ischaemia in the rabbit heart in vivo. Br J Anaesth. 1998;81:905-12.

26. Hale SL, Kloner RA. Ischemic preconditioning and myocardial hypothermia in rabbits with prolonged coronary artery occlusion. Am J Physiol. 1999;276:H2029-34.

27. Takeshima S, Vaage J, Lowbeer C, Valen G. Does hypothermia or hyperkalemia influence the preconditioning response? Scand Cardiovasc J. 1999;33:79-87.

28. Yamashita N, Shiro H, Kinya O, et al. Involvement of cytokines in the mechanism of whole-body hyperthermia-induced cardioprotection. Circulation. 2000;102:452-57.

29. Yamashita N, Nishida M, Hoshida S, et al. Induction of manganese superoxide dismutase in rat cardiac myocytes increases tolerance to hypoxia 24 hours after preconditioning. J Clin Invest. 1994;94:2193-9.

30. Matata B, Galiñanes M. Cardiopulmonary bypass exacerbates oxidative stress but does not increase proinflammatory cytokine release in patients with diabetes compared to patients without diabetes: regulatory effects of exogenous nitric oxide. J Thorac Cardiovasc Surg. 2000;120:1-11.

31. Richard VJ, Murry CE, Jennings RB, Reimer KA. Oxygen-derived free radicals and postischemic myocardial reperfusion: therapeutic implications. Fundam Clin Pharmacol. 1990;4:85-103.

32. Pain T, Yang XM, Critz SD, et al. Opening of mitochondrial K(ATP) channels triggers the preconditioned state by generating free radicals. Circ Res. 2000;87:460-6.

33. Speechly-Dick ME, Grover GJ, Yellon DM. Does ischemic preconditioning in the human involve PKC and the ATP-dependent $\mathrm{K}^{+}$channel. Circ Res. 1995;77:1020-35.

34. Heidbuchel H, Vereecke J, Carmeliet E. Three different potassium channels in human atrium: contribution to the basal potassium conductance. Circ Res. 1990;66:1277-86.

35. Banerjee A, Locke-Winter C, Rogers KB, et al. Preconditioning against myocardial dysfunction after ischemia and reperfusion by an alpha-adrenergic mechanism. Circ Res. 1993;73:656-70.

36. Cohen MV, Yang XM, Liu GS, Heusch G, Downey JM. Acetylcholine, bradykinin, opioids, and phenylephrine, but not adenosine, trigger preconditioning by generating free radicals and opening mitochondrial K(ATP) channels. Circ Res. 2001;89:273-8.

37. Loubani M, Galiñanes M. Alpha-1 adrenoreceptors during simulated ischemia and reoxygenation of the human myocardium: effect of the dose and time of administration. J Thorac Cardiovasc Surg. 2001;122: 103-12.

38. Thornton JD, Daly JF, Cohen MV, Yang X-M, Downey JM. Catecholamines can induce adenosine-receptor mediated protection of the myocardium but do not participate in ischemic preconditioning in the rabbit. Circ Res. 1991;73:649-55. 